\title{
Is the age of $>65$ years a risk factor for endoscopic treatment of primary inguinal hernia? Analysis of 24,571 patients from the Herniamed Registry
}

\author{
F. Mayer ${ }^{1} \cdot$ M. Lechner ${ }^{1} \cdot$ D. Adolf ${ }^{2} \cdot$ D. Öfner ${ }^{1} \cdot$ G. Köhler ${ }^{3} \cdot$ R. Fortelny ${ }^{4} \cdot$ \\ R. Bittner ${ }^{5}$ - F. Köckerling 6
}

Received: 27 January 2015/ Accepted: 31 March 2015/Published online: 22 April 2015

(c) The Author(s) 2015. This article is published with open access at Springerlink.com

\begin{abstract}
Introduction Several analyses of hernia registries have demonstrated that patients older than 65 years have significantly higher perioperative complication rates compared with patients up to the age of 65 . To date, no special analyses of endoscopic/laparoscopic inguinal hernia surgery or of the relevant additional influence factors have been carried out. Besides, there is no definition to determine whether 65 years should really be considered to be the age limit.

Methods In the Herniamed Hernia Registry, it was possible to identify 24,571 patients with a primary inguinal hernia and aged at least 16 years who had been operated on between September 1, 2009, and April 15, 2013, using either the TAPP technique $(n=17,214)$ or TEP technique $(n=7,357)$. Patients in the age group up to and including 65 years ( $\leq 65$ years) were compared with those older than
\end{abstract}

F. Mayer and M. Lechner contributed equally to the publication.

F. Köckerling

ferdinand.koeckerling@vivantes.de

1 Department of Surgery, Paracelsus Medical University, Salzburg, Austria

2 StatConsult GmbH, Magdeburg, Germany

3 Department of General and Visceral Surgery, Sisters of Charity Hospital, Linz, Austria

4 Department of General Surgery, Wilhelminenspital, Vienna, Austria

5 Hernia Center, Winghofer Medicum, Rottenburg am Neckar, Germany

6 Department of Surgery and Center of Minimally Invasive Surgery, Academic Teaching Hospital of Charité Medical School, Vivantes Hospital, Neue Bergstraße 6, 13585 Berlin, Germany
65 years ( $>65$ years) in terms of their perioperative outcome. That was done first using unadjusted analysis and then multivariable analysis.

Results Unadjusted analysis revealed significantly different results for the intraoperative (1.19 vs $1.60 \%$; $p=0,010)$, postoperative surgical $(2.72$ vs $4.59 \%$; $p<0.001)$ and postoperative general complications $(0.85$ vs $1.98 \% ; p<0.001)$ as well as for complication-related reoperations ( 1.07 vs $1.37 \% ; p=0,044)$, which were more favorable in the $\leq 65$ years age group. However, in multivariable analysis, it was not possible to confirm that for the intraoperative complications or the reoperations. Reoperations were needed more often for bilateral procedures $(p<0.001$; OR 2.154 [1.699; 2.730]), higher ASA classification (IV vs I: $p=0.004$; OR 6.001 [1.786; 20.167]), larger hernia defect and scrotal hernias. The impact of these factors, in addition to that of age $>65$ years, was also reflected in the postoperative complication rates. The age limit for increased onset of perioperative complication rates tends to be more than 80 rather than 65 years.

Conclusion The higher perioperative complication rate associated with endoscopic/laparoscopic inguinal hernia surgery in patients older than 65 years is of multifactorial genesis and is observed in particular as from the age of 80 years.

Keywords Inguinal hernia - TAPP - TEP .

Complications $\cdot$ Age $\cdot$ Reoperation

The demographics of western society are undergoing a significant change, with an increasingly elderly population. Inguinal hernia repair remains the most frequent surgical intervention in the west, and the impact of changing patient 
demographics means an increasing number of elderly patients require elective surgical repair. Incidence is also higher in the elderly, as loss of tissue strength leads to increased herniation [1-3].

On the basis of the 2006 National Hospital Discharge Survey, patients aged 65 and older accounted for $35 \%$ of all procedures [4]. A nationwide prevalence study showed that the age distribution of inguinal hernia repair is bimodal peaking at early childhood and old age (75-80 years) [5]. The cumulative incidence of inguinal hernia in the USA varies according to the patients' age: 25 - to 39 -year-old patients show an incidence of $7.3,14.8 \%$ at the age of 40-59 years and $22.8 \%$ at the age of more than 60 years [6].

The main goals of elective hernia surgery are symptomatic improvement and prevention of acute surgical emergencies such as incarceration or strangulation. Emergency repair is known to carry significantly higher rates of morbidity and mortality, especially among the elderly [7, 8]. However, there remains a lack of clarity about the appropriateness of intervention in elderly patients with comorbidity in whom symptoms may be minimal and elective repair carries risk [9]. Although a period of watchful waiting has been advocated by some authors for young fit patients, for older patients with comorbidity early elective repair has been advocated $[10,11]$.

Outcome studies demonstrate that morbidity and mortality are increased following surgery in the elderly as compared with the younger population [12].

In the Swedish Hernia Registry, there was a significant and substantial increase in risk of a postoperative complication with laparoscopic and open preperitoneal procedures in older patient (age $>65$ years) [13]. In the Danish Hernia Registry, complications after groin hernia repair were more frequent in patient $>65$ years $(4.5 \%)$, compared with younger patients $(2.7 \%)(p=0.001)$ [14].

In the National Surgical Quality Improvement Program (NSQIP) of the American College of Surgeons, the risk of onset of perioperative complications in patients $>65$ years is expressed with a significant higher odds ratio of 1.418 [1.206-1.666] [15].

Cardiac events occur in 1-5\% of patients undergoing non-cardiac surgery and pulmonary complications in $2.1-10.2 \%$ of elderly patients [4].

The use of a low-pressure pneumoperitoneum and of alternative gases to the $\mathrm{CO}_{2}$ pneumoperitoneum is under discussion in order to reduce the cardiopulmonary complications associated with laparoscopic/endoscopic surgery $[16,17]$. Other authors exclude older patients with important comorbidities such as severe chronic obstructive pulmonary disease (COPD) from laparoscopic/endoscopic surgical procedures [18].

In the prospective randomized Veterans Affairs Cooperative Study, it was not possible to identify any link between the patient's age and onset of short-term complications following laparoscopic/endoscopic inguinal hernia surgery ( $n=989$ patients) [19]. In a retrospective comparative study with 185 patients, no difference was discerned in the perioperative complication rates between patients $>65$ and $\leq 65$ years [18].

In retrospective comparative studies with 104 and 81 patients, no significant difference was seen in the perioperative outcome of patients aged $\geq 80$ years between open and laparoscopic/endoscopic inguinal hernia repair [20, 21].

In an effort to minimize elective operative morbidity and enhance postoperative recovery, laparoscopic repair has been suggested as an appropriate technique to inguinal hernia repair $[8,22,23]$.

Existing guidelines do not make any age-specific recommendations on optimal surgical approach in inguinal hernia surgery. There remains a lack of clarity about the safety of laparoscopic repair in an aging population [20,21].

This study therefore aimed to clarify the impact of age on postoperative outcome after endoscopic repair of primary inguinal hernia, as well as attempting to identify other influence factors that impacted the perioperative outcome and a cutoff age at which laparoscopic repair should no longer be advocated.

\section{Patients and methods}

Herniamed is a multicenter, internet-based hernia registry [24] in which 358 participating clinics and surgeons in private practice from Germany, Austria and Switzerland (Status: April 15, 2013) have prospectively registered their patients who had undergone hernia operations [14]. This present analysis now examines the prospective data of all patients who had undergone laparoscopic/endoscopic inguinal hernia repair in transabdominal preperitoneal patch plasty (TAPP) or total extraperitoneal patch plasty (TEP) between September 1, 2009, and April 15, 2013. The inclusion criteria were a minimum age of 16 years, primary inguinal hernia and uni- or bilateral operation. In total, 24,571 patients were enrolled (Table 1). These comprised 17,214 patients aged $\leq 65$ years $(70.1 \%)$ and 7357 patients aged $>65$ years $(29.9 \%)$ (Table 1$)$.

The groups were formed by dichotomizing the continuous variable 'age' into ' $\leq 65$ years' and ' $>65$ years.' In addition, the relationship of age to the categories of variables of interest is presented and discussed.

Table 1 Classification of patients into age groups

\begin{tabular}{lrr}
\hline Age & \multicolumn{1}{c}{$n$} & \multicolumn{1}{c}{$\%$} \\
\hline$\leq 65$ years & 17,214 & 70.06 \\
>65 years & 7357 & 29.94 \\
Overall & 24,571 & 100.00 \\
\hline
\end{tabular}


The demographic and surgery-related parameters included sex $(\mathrm{m} / \mathrm{f})$, ASA classification (I-IV), risk factors, previous operations and hernia defect sizes based on EHS classification (grade I-III), proportion of scrotal hernias, type of anesthesia, elective or emergency and inpatient vs outpatient treatment. The outcome variables defined were the intra- and postoperative as well as general complication rates, reoperation rate, duration of operation and length of hospital stay. Categorical data are presented as absolute and relative frequencies; continuous variables are displayed as mean, median, standard deviation, quantiles and ranges. In the case of skewed distributions as seen for durations, data were log-transformed. For the bilateral patient group, data on the variables given for both sides operated on were aggregated. For inguinal hernia defects of different sizes, the side with the larger defect is given. Classification as scrotal hernia was based on the presence of at least one scrotal hernia for bilateral inguinal hernia. Intra- and postoperative complications were recorded if a complication presented on at least one side. The same method was used to present details of any reoperation.

All analyses were performed with the software SAS 9.2 (SAS Institute Inc. Cary, NY, USA) and deliberately reviewed to the full level of significance. Each $p$ value $\leq 0.05$ thus represents a statistically significant result.

After investigating dependency of outcome variables (intra- and postoperative as well as general complications, reoperation rate, duration of operation and length of postoperative hospital stay) on individual factors (age and other characteristics of patients as well as operation) in unadjusted, univariable analyses (Chi-square test, $t$ test), multivariable models (continuously scaled outcome: general linear models, binary-scaled outcome: generalized linear models with logit link function) were applied, thus making it possible to analyze the influence of age adjusted by other possible influencing variables. The parameters of models and their corresponding $95 \%$ confidence intervals are reported as results - odds ratios in case of logistic regression and beta estimates in case of general linear models.

The validity of the logistic models was investigated by means of LOESS regression allowing visualization of the relationship between influencing variable and outcome. Only if a monotone increasing or decreasing relationship is seen is the model valid.

\section{Results}

\section{Unadjusted results}

Unadjusted analyses of the influence exerted by patient classification into age groups on patient characteristic variables (Table 2) showed that the patients in the two age
Table 2 Demographic data

\begin{tabular}{|c|c|c|c|c|c|}
\hline & \multicolumn{2}{|c|}{$\leq 65$ years } & \multicolumn{2}{|c|}{$>65$ years } & \multirow[t]{2}{*}{$p$} \\
\hline & $n$ & $\%$ & $n$ & $\%$ & \\
\hline \multicolumn{6}{|l|}{ Sex } \\
\hline Male & 15,481 & 89.93 & 6351 & 86.33 & \multirow[t]{2}{*}{$<0.001$} \\
\hline Female & 1733 & 10.07 & 1006 & 13.67 & \\
\hline \multicolumn{6}{|l|}{ ASA score } \\
\hline I & 7578 & 44.02 & 797 & 10.83 & \multirow[t]{4}{*}{$<0.001$} \\
\hline II & 8659 & 50.30 & 4523 & 61.48 & \\
\hline III & 968 & 5.62 & 1997 & 27.14 & \\
\hline IV & 9 & 0.05 & 40 & 0.54 & \\
\hline \multicolumn{6}{|c|}{ Defect size (EHS) } \\
\hline $\mathrm{I}(<1.5 \mathrm{~cm})$ & 3300 & 19.17 & 711 & 9.66 & \multirow[t]{3}{*}{$<0.001$} \\
\hline II $(1.5-3 \mathrm{~cm})$ & 10,883 & 63.22 & 4396 & 59.75 & \\
\hline III $(>3 \mathrm{~cm})$ & 3031 & 17.61 & 2250 & 30.58 & \\
\hline \multicolumn{6}{|c|}{ Scrotal hernia (EHS) } \\
\hline No & 16,851 & 97.89 & 7110 & 96.64 & \multirow[t]{2}{*}{$<0.001$} \\
\hline Yes & 363 & 2.11 & 247 & 3.36 & \\
\hline \multicolumn{6}{|l|}{ Anesthesia } \\
\hline Local & 14 & 0.08 & 6 & 0.08 & \multirow[t]{3}{*}{1.000} \\
\hline Spinal & 34 & 0.20 & 14 & 0.19 & \\
\hline General & 17,166 & 99.72 & 7337 & 99.73 & \\
\hline \multicolumn{6}{|c|}{ Inpatient/outpatient } \\
\hline Outpatient & 1020 & 5.93 & 194 & 2.64 & \multirow[t]{2}{*}{$<0.001$} \\
\hline Inpatient & 16,194 & 94.07 & 7163 & 97.36 & \\
\hline \multicolumn{6}{|c|}{ Degree of urgency } \\
\hline Elective & 17,061 & 99.11 & 7213 & 98.04 & \multirow[t]{2}{*}{$<0.001$} \\
\hline Emergency & 153 & 0.89 & 144 & 1.96 & \\
\hline \multicolumn{6}{|c|}{ Operation technique } \\
\hline TEP & 6636 & 38.55 & 2759 & 37.50 & \multirow[t]{2}{*}{0.122} \\
\hline TAPP & 10578 & 61.45 & 4598 & 62.50 & \\
\hline \multicolumn{6}{|c|}{ Unilateral/bilateral } \\
\hline Unilateral & 12,276 & 71.31 & 5311 & 72.19 & \multirow[t]{2}{*}{0.165} \\
\hline Bilateral & 4938 & 28.69 & 2046 & 27.81 & \\
\hline
\end{tabular}

groups differed significantly from each other with regard to the majority of the variables analyzed. For example, the proportion of women in the age group over 65 years was significantly greater $(p<0.001)$. Likewise, in that age group, there were significantly more higher ASA classifications, larger hernia defects and more emergency operations (in each case $p<0.001$ ). However, it must be borne in mind that due to the large number of cases even small, possibly clinically irrelevant, differences are identified as being significant.

A pronounced significant difference was found in the risk factors as well as in the rate of previous operations (Table 3). In the age group up to and including 65 years, $21.74 \%$ of patients had at least one risk factor, whereas in the age group older than 65 years that applied for almost 
one-third of patients $(p<0.001)$. Analysis of individual risk factors revealed that, apart from nicotine abuse, all risk factors were represented more commonly in the higher age group. As expected, that was also the case for the rate of previous operations. At $36.66 \%$, the rate of previous operations was significantly lower in the younger age group

Table 3 Risk factors

\begin{tabular}{|c|c|c|c|c|c|}
\hline & \multicolumn{2}{|c|}{$\leq 65$ years } & \multicolumn{2}{|c|}{$>65$ years } & \multirow[t]{2}{*}{$p$} \\
\hline & $n$ & $\%$ & $n$ & $\%$ & \\
\hline \multicolumn{6}{|c|}{ Risk factors } \\
\hline \multicolumn{6}{|c|}{ Overall } \\
\hline No & 13,471 & 78.26 & 4970 & 67.55 & \multirow[t]{2}{*}{$<0.001$} \\
\hline Yes & 3743 & 21.74 & 2387 & 32.45 & \\
\hline \multicolumn{6}{|c|}{ Aortic aneurysm } \\
\hline No & 17,196 & 99.90 & 7313 & 99.40 & \multirow[t]{2}{*}{$<0.001$} \\
\hline Yes & 18 & 0.10 & 44 & 0.60 & \\
\hline \multicolumn{6}{|c|}{ Antiplatelet medication } \\
\hline No & 16,732 & 97.20 & 6402 & 87.02 & \multirow[b]{2}{*}{$<0.001$} \\
\hline Yes & 482 & 2.80 & 955 & 12.98 & \\
\hline \multicolumn{6}{|c|}{ COPD } \\
\hline No & 16,524 & 95.99 & 6784 & 92.21 & \\
\hline Yes & 690 & 4.01 & 573 & 7.79 & $<0.001$ \\
\hline \multicolumn{6}{|c|}{ Corticoids } \\
\hline No & 17,104 & 99.36 & 7270 & 98.82 & \\
\hline Yes & 110 & 0.64 & 87 & 1.18 & $<0.001$ \\
\hline \multicolumn{6}{|c|}{ Diabetes } \\
\hline No & 16,752 & 97.32 & 6821 & 92.71 & \\
\hline Yes & 462 & 2.68 & 536 & 7.29 & $<0.001$ \\
\hline \multicolumn{6}{|c|}{ Coagulopathy } \\
\hline No & 17,098 & 99.33 & 7207 & 97.96 & \\
\hline Yes & 116 & 0.67 & 150 & 2.04 & $<0.001$ \\
\hline \multicolumn{6}{|c|}{ Immunosuppression } \\
\hline No & 17,135 & 99.54 & 7303 & 99.27 & \\
\hline Yes & 79 & 0.46 & 54 & 0.73 & 0.010 \\
\hline \multicolumn{6}{|c|}{ Anticoagulation therapy } \\
\hline No & 17,140 & 99.57 & 7077 & 96.19 & \\
\hline Yes & 74 & 0.43 & 280 & 3.81 & $<0.001$ \\
\hline \multicolumn{6}{|c|}{ Smoking } \\
\hline No & 14,836 & 86.19 & 6988 & 94.98 & \\
\hline Yes & 2378 & 13.81 & 369 & 5.02 & $<0.001$ \\
\hline
\end{tabular}

compared with the $>65$ year olds, where more than one out of every two patients had had at least one previous operation $(p<0.001)$.

The unadjusted tests of the influence of age groups on the outcome parameters (Tables 4, 5) showed a significant difference in all perioperative complication rates, reoperation rate as well as in the duration of operation and the length of postoperative hospital stay.

While the median length of hospital stay (Table 4) in both age groups was 2 days, a significant difference of 0.2 days was identified for the mean value, which was more favorable in the younger age category $(p<0.001)$. The significant difference in the duration of operation, which was on average $1.2 \mathrm{~min}$, was accordingly small.

Overall, there were $0.41 \%$ more intraoperative complications in the $>65$ years age group $(p=0.010)$, which was largely due a higher rate of intestinal injuries and bleeding (Table 5). The difference in postoperative complications at 2.72 versus $4.59 \%$ was even more pronounced to the disadvantage of the $>65$ years age group $(p<0.001)$. That was imputable in particular to the higher rate of secondary bleeding and of seromas. There was also a difference of $0.3 \%$ in the reoperation rate, again to the disadvantage of the $>65$ years age group $(p=0.044)$. There were twice as many general complications in the $>65$ years age group $(0.85$ vs $1.98 \%, p<0.001)$. The main complications seen were coronary heart disease, myocardial infarction, renal and cardiac failure, pleural effusion and pneumonia, and these occurred more often in the $>65$ years age group.

\section{Multivariable results}

Because of the differences in the patient characteristics between the two groups, and in particular due to the potential influence exerted by these variables on the outcome variables, unadjusted analysis of the complication rates with respect to age groups can lead to distortions. The results were verified using multivariable models.

Model fit of intraoperative complications, which reflects the suitability of the influence parameters for explaining the values of the outcome variables, was not significant $(p=0.199)$. Therefore, it was not possible to find any evidence that individual variables had a significant influence on onset of intraoperative complications.

Table 4 Unadjusted analysis of duration of operation and postoperative hospital stay

\begin{tabular}{|c|c|c|c|c|c|c|c|}
\hline & \multicolumn{3}{|l|}{$\leq 65$ years } & \multicolumn{3}{|l|}{$>65$ years } & \multirow[t]{2}{*}{$p$} \\
\hline & Mean-STD & Mean & Mean + STD & Mean-STD & MW & Mean + STD & \\
\hline Duration of operation [min] & 33.1 & 51.0 & 78.6 & 33.6 & 52.2 & 81.2 & $<0.001$ \\
\hline Post-op. hospital stay [days] & 1.0 & 1.6 & 2.6 & 1.1 & 1.8 & 3.1 & $<0.001$ \\
\hline
\end{tabular}


Table 5 Unadjusted analysis of perioperative complications and reoperations

\begin{tabular}{|c|c|c|c|c|}
\hline \multicolumn{2}{|c|}{$\leq 65$ years } & \multicolumn{2}{|c|}{$>65$ years } & $p$ \\
\hline$n$ & $\%$ & $n$ & $\%$ & \\
\hline
\end{tabular}

Intraoperative complications

Overall

$\begin{array}{crrrrr}\text { Yes } & 205 & 1.19 & 118 & 1.60 & \\ \text { No } & 17,009 & 98.81 & 7239 & 98.40 & 0.010 \\ \text { Bleeding } & & & & & \\ \text { Yes } & 138 & 0.80 & 75 & 1.02 & \\ \text { No } & 17,076 & 99.20 & 7282 & 98.98 & 0.098\end{array}$

Injuries

Overall

$\begin{array}{crrrrr}\text { Yes } & 116 & 0.67 & 65 & 0.88 & \\ \text { No } & 17,098 & 99.33 & 7292 & 99.12 & 0.078 \\ \text { Vascular } & & & & & \\ \text { Yes } & 53 & 0.31 & 19 & 0.26 & \\ \text { No } & 17,161 & 99.69 & 7338 & 99.74 & 0.606 \\ \text { Bowel } & & & & & \\ \text { Yes } & 11 & 0.06 & 14 & 0.19 & \\ \text { No } & 17,203 & 99.94 & 7343 & 99.81 & 0.007 \\ \text { Bladder } & & & & & \\ \text { Yes } & 16 & 0.09 & 13 & 0.18 & \\ \text { No } & 17,198 & 99.91 & 7344 & 99.82 & 0.103 \\ \text { Nerve } & & & & & \\ \text { Yes } & 1 & 0.01 & 0 & 0.00 & \\ \text { No } & 17,213 & 99.99 & 7357 & 100.0 & 1.000\end{array}$

Postoperative complications

Overall

$\begin{array}{lrrrrr}\text { Yes } & 468 & 2.72 & 338 & 4.59 & \\ \text { No } & 16,746 & 97.28 & 7019 & 95.41 & <0.001 \\ \text { Bleeding } & & & & & \\ \text { Yes } & 121 & 0.70 & 110 & 1.50 & \\ \text { No } & 17,093 & 99.30 & 7247 & 98.50 & <0.001\end{array}$

Bowel injury/anastomotic leakage

\begin{tabular}{lrrrrr} 
Yes & 6 & 0.03 & 3 & 0.04 & \\
No & 17,208 & 99.97 & 7354 & 99.96 & 0.733 \\
SSI & & & & & \\
Yes & 19 & 0.11 & 4 & 0.05 & \\
$\quad$ No & 17,195 & 99.89 & 7353 & 99.95 & 0.255 \\
Seroma & & & & & \\
$\quad$ Yes & 319 & 1.85 & 224 & 3.04 & \\
$\quad$ No & 16,895 & 98.15 & 7133 & 96.96 & $<0.001$ \\
Mesh infection & & & & & \\
Yes & 10 & 0.06 & 1 & 0.01 & \\
No & 17,204 & 99.94 & 7356 & 99.99 & 0.191 \\
Ileus & & & & & \\
Yes & 13 & 0.08 & 8 & 0.11 & \\
No & 17,201 & 99.92 & 7349 & 99.89 & 0.475 \\
\hline
\end{tabular}

Table 5 continued

\begin{tabular}{|c|c|c|c|c|c|}
\hline & \multicolumn{2}{|c|}{$\leq 65$ years } & \multicolumn{2}{|c|}{$>65$ years } & \multirow[t]{2}{*}{$p$} \\
\hline & $n$ & $\%$ & $n$ & $\%$ & \\
\hline \multicolumn{6}{|c|}{ Reoperation } \\
\hline Yes & 184 & 1.07 & 101 & 1.37 & \\
\hline No & 17,030 & 98.93 & 7256 & 98.63 & 0.044 \\
\hline \multicolumn{6}{|c|}{ General complications } \\
\hline \multicolumn{6}{|l|}{ Overall } \\
\hline Yes & 147 & 0.85 & 146 & 1.98 & \\
\hline No & 17,067 & 99.15 & 7211 & 98.02 & $<0.001$ \\
\hline \multicolumn{6}{|c|}{ Urinary tract infection } \\
\hline Yes & 14 & 0.08 & 7 & 0.10 & \\
\hline No & 17,200 & 99.92 & 7350 & 99.90 & 0.812 \\
\hline \multicolumn{6}{|c|}{ Thrombosis } \\
\hline Yes & 4 & 0.02 & 3 & 0.04 & \\
\hline No & 17,210 & 99.98 & 7354 & 99.96 & 0.434 \\
\hline \multicolumn{6}{|c|}{ Pulmonary embolism (PAE) } \\
\hline Yes & 2 & 0.01 & 3 & 0.04 & \\
\hline No & 17,212 & 99.99 & 7354 & 99.96 & 0.162 \\
\hline \multicolumn{6}{|c|}{ Pneumonia } \\
\hline Yes & 3 & 0.02 & 9 & 0.12 & \\
\hline No & 17,211 & 99.98 & 7348 & 99.88 & 0.002 \\
\hline \multicolumn{6}{|l|}{ COPD } \\
\hline Yes & 8 & 0.05 & 9 & 0.12 & \\
\hline No & 17,206 & 99.95 & 7348 & 99.88 & 0.059 \\
\hline \multicolumn{6}{|c|}{ Myocardial infarction } \\
\hline Yes & 3 & 0.02 & 11 & 0.15 & \\
\hline No & 17211 & 99.98 & 7346 & 99.85 & $<0.001$ \\
\hline \multicolumn{6}{|c|}{ Renal failure } \\
\hline Yes & 2 & 0.01 & 11 & 0.15 & \\
\hline No & 17212 & 99.99 & 7346 & 99.85 & $<0.001$ \\
\hline \multicolumn{6}{|c|}{ Death } \\
\hline Yes & 1 & 0.01 & 4 & 0.05 & \\
\hline No & 17213 & 99.99 & 7353 & 99.95 & 0.031 \\
\hline
\end{tabular}

The results of analysis of the postoperative complications are illustrated in Table 6 (model fit: $p<0.001$ ). The postoperative complication rate is impacted primarily by an advanced hernia disease and the general condition of the patient. Scrotal EHS classification also resulted in an increased complication risk (OR 2.738 [2.078; 3.609]). Likewise, a larger hernia defect significantly increased the postoperative complication risk ( $p<0,001$; II vs I: OR 1.677 [1.285; 2.187]; III vs I: OR 2.471 [1.855; 3.292]). Equally, the overall complication risk was significantly increased by the use of transabdominal preperitoneal patch plasty (TAPP) (OR 2.461 [2.066; 2.931]). With regard to the postoperative complications, as demonstrated by unadjusted analysis, a significantly lower complication risk was identified in the 
Table 6 Multivariable analysis of postoperative complications

\begin{tabular}{lcllll}
\hline Parameter & $p$ value & Variables & OR & 95 \% CI \\
\hline Operation technique & $<0.001$ & TAPP vs TEP & 2.461 & 2.066 & 2.931 \\
Scrotal hernia (EHS) & $<0.001$ & Yes vs No & 2.738 & 2.078 & 3.609 \\
Defect size (EHS) & $<0.001$ & II $(1.5-3 \mathrm{~cm})$ vs I $(<1.5 \mathrm{~cm})$ & 1.677 & 1.285 & 2.187 \\
& & III $(>3 \mathrm{~cm})$ vs I $(<1.5 \mathrm{~cm})$ & 2.471 & 1.855 & 3.292 \\
Age & $<0.001$ & $\leq 65$ vs $>65$ years & 0.718 & 0.612 & 0.841 \\
ASA score & 0.037 & II vs I & 1.161 & 0.976 & 1.381 \\
& & III vs I & 1.362 & 1.071 & 1.732 \\
& & IV vs I & 2.559 & 0.891 & 7.346 \\
Bilateral/unilateral & 0.041 & Bilateral vs unilateral & 1.173 & 1.007 & 1.366 \\
Sex & 0.304 & Male vs female & 0.884 & 0.699 & 1.118 \\
\hline
\end{tabular}

Table 7 Multivariable analysis of reoperation

\begin{tabular}{lclllr}
\hline Parameter & $p$ value & Variables & OR & \multicolumn{2}{c}{95 CI } \\
\hline Bilateral/unilateral & $<0.001$ & Bilateral vs unilateral & 2.154 & 1.699 & 2.730 \\
ASA score & 0.004 & II vs I & 1.058 & 0.799 & 1.401 \\
& & III vs I & 1.581 & 1.074 & 2.327 \\
& & IV vs I & 6.001 & 1.786 & 20.167 \\
Scrotal hernia (EHS) & 0.033 & Yes vs No & 1.807 & 1.049 & 3.111 \\
Defect size (EHS) & 0.043 & II $(1.5-3 \mathrm{~cm})$ vs I $(<1.5 \mathrm{~cm})$ & 1.208 & 0.819 & 1.780 \\
& & III $(>3 \mathrm{~cm})$ vs I $(<1.5 \mathrm{~cm})$ & 1.614 & 1.051 & 2.478 \\
Operation technique & 0.463 & TAPP vs TEP & 1.096 & 0.858 & 1.399 \\
Age & 0.695 & $\leq 65$ vs $>65$ years & 0.947 & 0.721 & 1.244 \\
Sex & 0.918 & Male vs female & 0.979 & 0.650 & 1.474 \\
\hline
\end{tabular}

$\leq 65$ years age group ( $p<0.001$; OR 0.718 [0.612; 0.841]) Low ASA classifications ( $p=0.037$; II vs I: OR 1.161 [0.976; 1.381]; III vs I: OR 1.362 [1.071; 1.732]; IV vs I: OR $2.559[0.891 ; 7.346])$ and a unilateral operation $(p=0.041$; OR 1.173 [1.007; 1.366]) also significantly reduced occurrence of a postoperative complication.

With a prevalence of $3.28 \%$, that corresponds to 28 postoperative complications for every 1,000 patients from the $\leq 65$ years age group compared with 38 complications for the $>65$ years age group.

The results of analysis of the reoperation rate are given in Table 7 (model fit: $p<0.001$ ). The reoperation rate was influenced primarily by bilaterality of the inguinal hernia operation $(p<0.001)$. Conduct of a bilateral surgical procedure led to significantly more reoperations (OR 2.154 [1.669; 2.730]). Likewise, high ASA classifications resulted significantly more often in reoperation ( $p=0.004$; II vs I: OR 1.058 [0.799; 1.401]; III vs I: OR 1.581; [1.074; 2.327]; IV vs I: OR $6.001[1.786 ; 20.167])$. The risk of reoperation also rose for scrotal inguinal hernias ( $p=0.033$; OR 1.807 [1.049; 3.111]). The same applied for a large hernia defect ( $p=0.043$ : II vs I: OR 1.208 [0.819; 1.780]; III vs I: OR 1.614 [1.051; 2.478]).

Conversely - and contrary to the findings of unadjusted analysis - the reoperation rate did not differ significantly between the two age groups investigated.
Table 8 gives the results of multivariable analysis of the influences impacting general complications (model fit: $p<0.001)$. The general complications were influenced primarily by ASA status $(p<0.001)$. In particular, ASA classification IV increased the complication risk (IV vs I: OR 6.355 [1.892; 21.345]). Onset of general complications was likewise significantly more common in the $>65$ years age group than in the $\leq 65$ years age group ( $p<0.001$; OR $0.615[0.473 ; 0.800])$. The use of the TAPP operation method also favored onset of general complications ( $p=0.005)$. The corresponding risk rose for a TAPP operation with an odds ratio of OR 1.432 [1.114; 1.841].

For an overall general complication rate of $1.19 \%$, that corresponds to occurrence of a complication in around 10 out of every 1000 patients undergoing surgery from the $\leq 65$ years age group compared with 14 out of every 1000 patients for the $>65$ years age group.

Model fit of the duration of operation was also highly significant ( $p<0.001)$. The highly significant impact of the age groups on the duration of operation, which was demonstrated in unadjusted analysis, could only be confirmed as a trend in the multivariable model (Table 9). In reality, a large hernia defect, the presence of a scrotal hernia, surgery for a male patient, the use of TAPP and bilateral operation (in each case $p<0.001$ ) led to significant increase in the duration of operation. 

of general complications
Table 8 Multivariable analysis

\begin{tabular}{lclllr}
\hline Parameter & $p$ value & Variables & OR & \multicolumn{2}{l}{$95 \%$ CI } \\
\hline ASA score & $<0.001$ & II vs I & 1.171 & 0.855 & 1.604 \\
& & III vs I & 3.419 & 2.381 & 4.911 \\
& & IV vs I & 6.355 & 1.892 & 21.345 \\
Age & $<0.001$ & S65 years vs $>65$ years & 0.615 & 0.473 & 0.800 \\
Operation technique & 0.005 & TAPP vs TEP & 1.432 & 1.114 & 1.841 \\
Bilateral/unilateral & 0.225 & Bilateral vs unilateral & 1.169 & 0.909 & 1.504 \\
Defect size (EHS) & 0.588 & II $(1.5-3 \mathrm{~cm})$ vs I $(<1.5 \mathrm{~cm})$ & 0.842 & 0.595 & 1.190 \\
& & III $(>3 \mathrm{~cm})$ vs I $(<1.5 \mathrm{~cm})$ & 0.906 & 0.608 & 1.352 \\
Scrotal hernia (EHS) & 0.665 & Yes vs No & 1.148 & 0.614 & 2.146 \\
Sex & 0.999 & Male vs female & 1.000 & 0.693 & 1.443 \\
\hline
\end{tabular}

Table 9 Multivariable analysis of duration of operation

\begin{tabular}{lllrrr}
\hline Parameter & $p$ value & Variables & \multicolumn{1}{l}{ Beta } & 95 \% CI & \\
\hline Intercept & $<0.001$ & & 3.717 & 3.603 & 3.831 \\
Bilateral & $<0.001$ & Bilateral & 0.313 & 0.301 & 0.324 \\
Operation technique & $<0.001$ & TAPP & 0.089 & 0.078 & 0.099 \\
Defect size (EHS) & $<0.001$ & I $(<1.5 \mathrm{~cm})$ & -0.113 & -0.131 & -0.096 \\
Defect size (EHS) & $<0.001$ & II $(1.5-3 \mathrm{~cm})$ & -0.097 & -0.110 & -0.084 \\
Scrotal hernia (EHS) & $<0.001$ & Yes & 0.182 & 0.149 & 0.216 \\
Sex & $<0.001$ & Male & 0.046 & 0.029 & 0.062 \\
ASA score & & I & 0.115 & 0.002 & 0.229 \\
ASA score & & II & 0.124 & 0.011 & 0.237 \\
ASA score & 0.024 & III & 0.108 & -0.006 & 0.222 \\
Age & 0.072 & $\leq 65$ Jahre & -0.011 & -0.023 & 0.001 \\
\hline
\end{tabular}

Table 10 Multivariable analysis of hospital stay

\begin{tabular}{lllrrr}
\hline Parameter & $p$ value & Variables & \multicolumn{1}{l}{ Beta } & \multicolumn{1}{l}{$95 \%$ CI } \\
\hline Intercept & $<0.001$ & & 1.107 & 0.967 & 1.246 \\
ASA score & $<0.001$ & I & -0.571 & -0.709 & -0.432 \\
ASA score & $<0.001$ & II & -0.524 & -0.662 & -0.386 \\
ASA score & $<0.001$ & III & -0.365 & -0.504 & -0.226 \\
Bilateral & $<0.001$ & Bilateral & 0.111 & 0.097 & 0.125 \\
Sex & $<0.001$ & Male & -0.124 & -0.145 & -0.104 \\
Scrotal hernia (EHS) & $<0.001$ & YES & 0.203 & 0.163 & 0.243 \\
Age & $<0.001$ & S65 years & -0.056 & -0.071 & -0.041 \\
Defect size (EHS) & $<0.001$ & I $(<1.5 \mathrm{~cm})$ & 0.014 & -0.008 & 0.035 \\
Defect size (EHS) & $<0.001$ & II $(1.5-3 \mathrm{~cm})$ & 0.039 & 0.023 & 0.055 \\
Operation technique & 0.020 & TAPP & 0.015 & 0.002 & 0.028 \\
\hline
\end{tabular}

Table 10 shows the results of multivariable analysis of the factors influencing the postoperative length of hospital stay (model fit: $p<0.001$ ). The postoperative length of hospital stay was significantly increased in the $>65$ years age group also, when concurrently looking at the other influencing variables $(p<0.001)$. All other influencing variables also had a significant impact on the length of stay. The length of hospital stay was increased in each case by the use of the TAPP operation method, bilaterality of operation as well as by a scrotal hernia. Besides, the postoperative stay was significantly longer for women than for men.

On the basis of the LOESS graphs, it can be seen that the proportion of higher ASA classifications and of risk factors rise almost linearly with increasing age (Fig. 1). The postoperative complications increase as from age 80 years (Fig. 1). 
Fig. 1 Non-metric regression analysis (LOESS) of age for post-op. complication, cumulative risk factors and ASA score

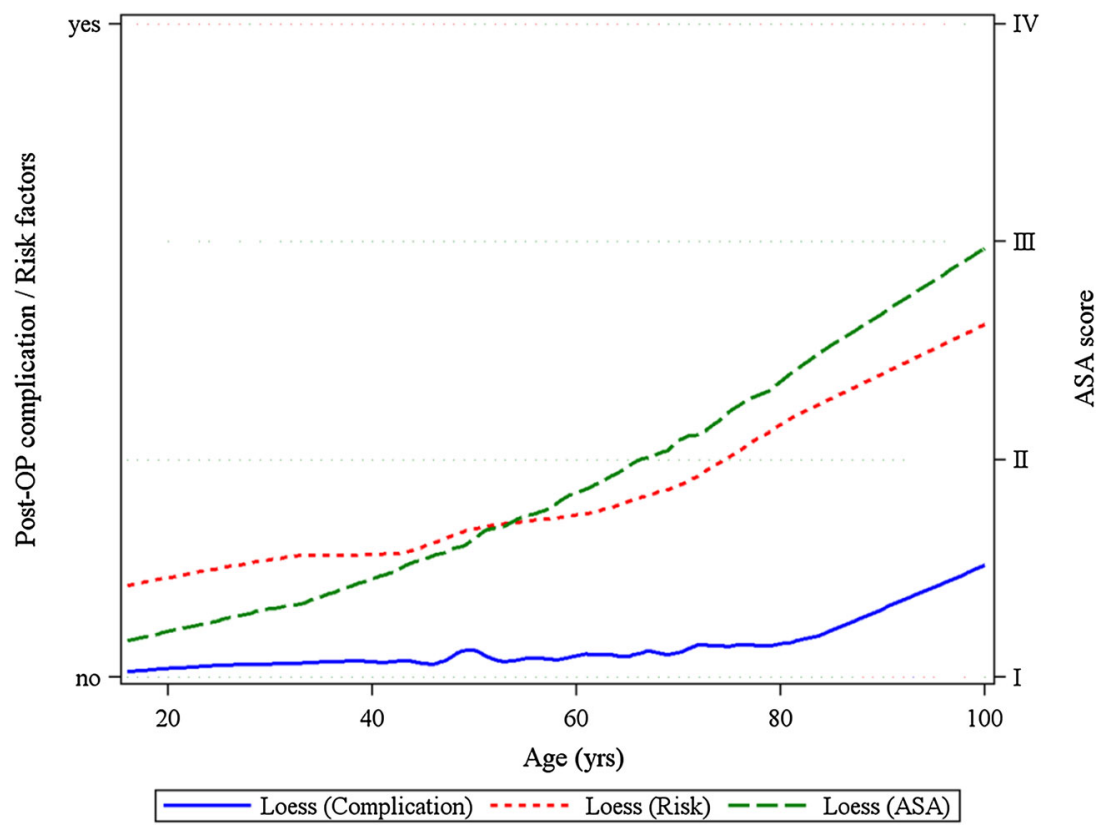

\section{Discussion}

The registry study presented here investigated the influence of patient age $>65$ years on the perioperative outcome compared with that of patient age $\leq 65$ years. In addition, other factors impacting onset of perioperative complications were identified and their relative influence on the results determined.

The patients in the two age groups differed significantly from each other with regard to the majority of the variables analyzed. For example, in the $>65$ years age group, the proportion of women, higher ASA classifications, larger hernia defects, emergency operations, risk factors and previous operations were significantly greater.

Unadjusted analyses revealed that patients in $>65$ years age group had significantly higher intraoperative, postoperative and general complication rates as well as a higher reoperation rate linked to these complications. In multivariable analysis, it was not possible to find any evidence that individual variables influenced onset of intraoperative complications. As regards the postoperative complications, multivariable analysis showed the risk identified for the $\leq 65$ years age group was significantly lower. Likewise, there were significantly fewer postoperative complications when using TEP, for smaller hernia defects, unilateral operation and a lower ASA classification. Conversely, scrotal EHS classification had an unfavorable influence on occurrence of postoperative complications. However, as in the TAPP group, the percentage of patients with scrotal hernias or with larger hernia defects is significantly higher compared with TEP both minimal invasive techniques are hardly comparable and conclusions should be drawn with caution.

On the other hand, the reoperation rate did not differ significantly between the two age groups in multivariable analysis. The probability of reoperation was increased by bilateral operations, a higher ASA classification, larger hernia defects as well as by a scrotal hernia, but not by the operation technique.

General complications were also seen in multivariable analysis significantly more often in the $>65$ years age group than in the younger patients. The TAPP operation method and a higher ASA classification are other unfavorable influence factors.

The postoperative length of hospital stay was significantly increased in the $>65$ years age group, also when concurrently looking at the other influencing variables.

The higher rate of postoperative surgical and general complications in patients in the $>65$ years age group compared with in the $\leq 65$ years age group thus concords with the findings of the Swedish Hernia Registry [13], Danish Hernia Registry [14] and of the National Surgical Quality Improvement Program of the American College of Surgeons [15]. However, the data presented here in this study additionally show that the age-related rise in postoperative surgical complications did not lead to an increased complication-related reoperation rate. Rather, it was more a bilateral operation, higher ASA classification, larger hernia defect and scrotal hernia which resulted in postoperative complications necessitating reoperation. These were also the influencing variables, in addition to TAPP, which apart from age $>65$ years gave rise to 
increased postoperative surgical complications, which could be treated conservatively. Accordingly, the higher perioperative complication rate associated with endoscopic/laparoscopic inguinal hernia surgery in patients $>65$ years compared with those $\leq 65$ years is of multifactorial genesis. The same applies for the general postoperative complications, which in the $>65$ years age group were further negatively influenced by conduct of TAPP operation and the presence of a higher ASA classification. That, too, demonstrates the multifactorial influence exerted on the postoperative outcome of patients in the $>65$ years age group.

The age limit of 65 years is used as a rule for analysis of the influence of age on the postoperative outcome following surgical procedures because of the fact that this is the retirement age in many countries [13]. However, our own analyses based on LOESS graphs show that age 80 years tends to be the time point from which a marked rise is seen in postoperative complications.

In summary, it can be stated that the increase in perioperative complication and reoperation rates associated with laparoscopic/endoscopic inguinal hernia surgery is not only influenced by higher age but mainly by other factors. These include, in particular, bilateral operation, large hernia defect or scrotal hernia and a higher ASA classification and a multitude of risk factors. It can also be demonstrated that it is only as from age 80 years that a relevant rise in postoperative complication rates can be identified. As such, age $>65$ years in itself does not constitute a risk factor for conduct of laparoscopic/endoscopic inguinal hernia repair. If this is indicated, the focus should be more on the factors identified by the presented study and which have a significant influence on the outcome. In patients over the age of 80, laparoscopic hernia repair is possible, but preoperative analysis of risk factors and their correction if possible should be mandatory [25]. Moreover, careful intraoperative monitoring by the anesthesiologist is essential and the possibility to stay for some hours in an ICU should be provided.

Acknowledgments Ferdinand Köckerling has got grants to fund the Herniamed Registry from Johnson\&Johnson, Norderstedt, Karl Storz, Tutlingen, PFM Medical, Cologne, Dahlhausen, Cologne, B Braun, Tutlingen, MenkeMed, Munich and BARD, Karlsruhe.

Disclosures F. Mayer, M. Lechner, D. Adolf, D. Öfner, G. Köhler, R, Fortelny, R. Bittner have no conflicts of interest or financial ties to disclose.

Open Access This article is distributed under the terms of the Creative Commons Attribution 4.0 International License (http:// creativecommons.org/licenses/by/4.0/), which permits unrestricted use, distribution, and reproduction in any medium, provided you give appropriate credit to the original author(s) and the source, provide a link to the Creative Commons license, and indicate if changes were made.

\section{Appendix: Herniamed Study Group}

\section{Scientific Board}

Köckerling, Ferdinand (Chairman); Berger, Dieter; Bittner, Reinhard; Fortelny, René; Koch, Andreas; Kraft, Barbara; Kuthe, Andreas; Lorenz, Ralph; Mayer, Franz; Moesta, Kurt Thomas; Niebuhr, Henning; Peiper, Christian; Pross, Matthias; Reinpold, Wolfgang; Simon, Thomas; Stechemesser, Bernd; Unger, Solveig

\section{Participants}

Ahmetov, Azat (Saint-Petersburg); Alapatt, Terence Francis (Frankfurt/Main); Anders, Stefan (Berlin); Anderson, Jürina (Würzburg); Arndt, Anatoli (Elmshorn); Asperger, Walter (Halle); Avram, Iulian (Saarbrücken); Barkus; Jörg (Velbert); Becker, Matthias (Freital); Behrend, Matthias (Deggendorf); Beuleke, Andrea (Burgwedel); Berger, Dieter (Baden-Baden); Bittner, Reinhard (Rottenburg); Blumberg, Claus (Lübeck); Böckmann, Ulrich (Papenburg); Böhle, Arnd Steffen (Bremen); Böttger, Thomas Carsten (Fürth); Borchert, Erika (Grevenbroich); Born, Henry (Leipzig); Brabender, Jan (Köln); Breitenbuch von, Philipp (Radebeul); Brüggemann, Armin (Kassel); Brütting, Alfred (Erlangen); Budzier, Eckhard (Meldorf); Burghardt, Jens (Rüdersdorf); Carus, Thomas (Bremen); Cejnar, Stephan-Alexander (München); Chirikov, Ruslan (Dorsten); Comman, Andreas (Bogen); Crescenti, Fabio (Verden/Aller); Dapunt, Emanuela (Bruneck); Decker, Georg (Berlin); Demmel, Michael (Arnsberg); Descloux, Alexandre (Baden); Deusch, Klaus-Peter (Wiesbaden); Dick, Marcus (Neumünster); Dieterich, Klaus (Ditzingen); Dietz, Harald (Landshut); Dittmann, Michael (Northeim); Dornbusch, Jan (Herzberg/Elster); Drummer, Bernhard (Forchheim); Eckermann, Oliver (Luckenwalde); Eckhoff, Jörn /Hamburg); Elger, Karlheinz (Germersheim); Engelhardt, Thomas (Erfurt); Erichsen, Axel (Friedrichshafen); Eucker, Dietmar (Bruderholz); Fackeldey, Volker (Kitzingen); Farke, Stefan (Delmenhorst); Faust, Hendrik (Emden); Federmann, Georg (Seehausen); Feichter, Albert (Wien); Fiedler, Michael (Eisenberg); Fischer, Ines (Wiener Neustadt); Fortelny, René H. (Wien); Franczak, Andreas (Wien); Franke, Claus (Düsseldorf); Frankenberg von, Moritz (Salem); Frehner, Wolfgang (Ottobeuren); Friedhoff, Klaus (Andernach); Friedrich, Jürgen (Essen); Frings, Wolfram (Bonn); Fritsche, Ralf (Darmstadt); Frommhold, Klaus (Coesfeld); Frunder, Albrecht (Tübingen); Fuhrer, Günther (Reutlingen); Gassler, Harald (Villach); Gerdes, Martin (Ostercappeln); Gilg, KaiUwe (Hartmannsdorf); Glaubitz, Martin (Neumünster); 
Glutig, Holger (Meißen); Gmeiner, Dietmar (Bad Dürrnberg); Göring, Herbert (München); Grebe, Werner (Rheda-Wiedenbrück); Grothe, Dirk (Melle); Gürtler, Thomas (Zürich); Hache, Helmer (Löbau); Hämmerle, Alexander (Bad Pyrmont); Haffner, Eugen (Hamm); Hain, Hans-Jürgen (Groß-Umstadt); Hammans, Sebastian (Lingen); Hampe, Carsten (Garbsen); Harrer, Petra (Starnberg); Heinzmann, Bernd (Magdeburg); Heitland, Tim (München); Helbling, Christian (Rapperswil); Hempen, Hans-Günther (Cloppenburg); Henneking, Klaus-Wilhelm (Bayreuth); Hermes, Wolfgang (Weyhe); Herrgesell, Holger (Berlin); Herzing, Holger Höchstadt); Hessler, Christian (Bingen); Hildebrand, Christiaan (Langenfeld); Höferlin, Andreas (Mainz); Hoffmann, Michael (Kassel; Hofmann, Eva M. (Frankfurt/Main); Hopfer, Frank (Eggenfelden); Hornung, Frederic (Wolfratshausen); Hügel, Omar (Hannover); Hüttemann, Martin (Oberhausen); Huhn, Ulla (Berlin); Imdahl, Andreas (Heidenheim); Jacob, Dietmar (Bielefeld); Jenert, Burghard (Lichtenstein); Jugenheimer, Michael (Herrenberg); Junger, Marc (München); Käs, Stephan (Weiden); Kahraman, Orhan (Hamburg); Kaiser, Christian (Westerstede); Kaiser, Stefan (Kleinmachnow); Kapischke, Matthias (Hamburg); Karch, Matthias (Eichstätt); Keck, Heinrich (Wolfenbüttel); Keller, Hans W. (Bonn); Kienzle, Ulrich (Karlsruhe); Kipfmüller, Brigitte (Köthen); Kirsch, Ulrike (Oranienburg); Klammer, Frank (Ahlen); Klatt, Richard (Hagen); Kleemann, Nils (Perleberg); Klein, Karl-Hermann (Burbach); Kleist, Sven (Berlin); Klobusicky, Pavol (Bad Kissingen); Kneifel, Thomas (Datteln); Knoop, Michael (Frankfurt/Oder); Knotter, Bianca (Mannheim); Koch, Andreas (Cottbus); Köckerling, Ferdinand (Berlin); Köhler, Gernot (Linz); König, Oliver (Buchholz); Kornblum, Hans (Tübingen); Krämer, Dirk (Bad Zwischenahn); Kraft, Barbara (Stuttgart); Kreissl, Peter (Ebersberg); Krones, Carsten Johannes (Aachen); Kruse, Christinan (Aschaffenburg); Kube, Rainer (Cottbus); Kühlberg, Thomas (Berlin); Kuhn, Roger (Gifhorn); Kusch, Eduard (Gütersloh); Kuthe, Andreas (Hannover); Ladberg, Ralf (Bremen); Ladra, Jürgen (Düren); LahrEigen, Rolf (Potsdam); Lainka, Martin (Wattenscheid); Lammers, Bernhard J. (Neuss); Lancee, Steffen (Alsfeld); Larusson, Hannes Jon (Pinneberg); Lauschke, Holger (Duisburg); Leher, Markus (Schärding); Leidl, Stefan (Waidhofen/Ybbs); Lenz, Stefan (Berlin); Lesch, Alexander (Kamp-Lintfort); Lienert, Mark (Duisburg); Limberger, Andreas (Schrobenhausen); Locher, Martin (Kiel); Loghmanieh, Siawasch (Viersen); Lorenz, Ralph (Berlin); Mallmann, Bernhard (Krefeld); Manger, Regina (Schwabmünchen); Maurer, Stephan (Münster); Mayer, Franz (Salzburg); Menzel, Ingo (Weimar); Meurer, Kirsten (Bochum); Meyer, Moritz (Ahaus); Mirow, Lutz (Kirchberg); Mittenzwey, Hans-Joachim (Berlin); Mörder-
Köttgen, Anja (Freiburg); Moesta, Kurt Thomas (Hannover); Moldenhauer, Ingolf (Braunschweig); Morkramer, Rolf (Xanten); Mosa, Tawfik (Merseburg); Müller, Hannes (Schlanders); Münzberg, Gregor (Berlin); Mussack, Thomas (St. Gallen); Neumann, Jürgen (Haan); Niebuhr, Henning (Hamburg); Nölling, Anke (Burbach); Nostitz, Friedrich Zoltán (Mühlhausen); Obermaier, Straubing); Öz-Schmidt, Meryem (Hanau); Oldorf, Peter (Usingen); Olivieri, Manuel (Pforzheim); Pawelzik, Marek (Hamburg); Peiper, Christian (Hamm); Pertl, Alexander (Spittal/Drau); Philipp, Mark (Rostock); Pickart, Lutz (Bad Langensalza); Pizzera, Christian (Graz); Pöllath, Martin (Sulzbach-Rosenberg); Possin, Ulrich (Laatzen); Prenzel, Klaus (Bad Neuenahr-Ahrweiler); Pröve, Florian (Goslar); Pronnet, Thomas (Fürstenfeldbruck); Pross, Matthias (Berlin); Puff, Johannes (Dinkelsbühl); Rabl, Anton (Passau); Rapp, Martin (Neunkirchen); Reck, Thomas (Püttlingen); Reinpold, Wolfgang (Hamburg); Reuter, Christoph (Quakenbrück); Richter, Jörg (Winnenden); Riemann, Kerstin (AlzenauWasserlos); Rodehorst, Anette (Otterndorf); Roehr, Thomas (Rödental); Roncossek, Bremerhaven); Roth Hartmut (Nürnberg); Sardoschau, Nihad (Saarbrücken); Sauer, Gottfried (Rüsselsheim); Sauer, Jörg (Arnsberg); Seekamp, Axel (Freiburg); Seelig, Matthias (Bad Soden); Seiler, Christoph Michael (Warendorf); Seltmann, Cornelia (Hachenburg); Senkal, Metin (Witten); Shamiyeh, Andreas (Linz); Shang, Edward (München); Siemssen, Björn (Berlin); Sievers, Dörte (Hamburg); Silbernik, Daniel (Bonn); Simon, Thomas (Sinsheim); Sinn, Daniel (Olpe); Sinning, Frank (Nürnberg); Smaxwil, Constatin Aurel (Stuttgart); Schabel, Volker (Kirchheim/Teck); Schadd, Peter (Euskirchen); Schassen von, Christian (Hamburg); Schattenhofer, Thomas (Vilshofen); Scheidbach, Hubert (Neustadt/Saale); Schelp, Lothar (Wuppertal); Scherf, Alexander (Pforzheim); Scheyer, Mathias (Bludenz); Schimmelpenning, Hendrik (Neustadt in Holstein); Schinkel, Svenja (Kempten); Schmid, Michael (Gera); Schmid, Thomas (Innsbruck); Schmidt, Rainer (Paderborn); Schmidt, Sven-Christian (Berlin); Schmidt, Ulf (Mechernich); Schmitz, Heiner (Jena); Schmitz, Ronald (Altenburg); Schöche, Jan (Borna); Schoenen, Detlef (Schwandorf); Schrittwieser, Rudolf /Bruck an der Mur); Schroll, Andreas (München); Schultz, Christian (Bremen-Lesum); Schultz, Harald (Landstuhl); Schulze, Frank P. Mülheim an der Ruhr); Schumacher, Franz-Josef (Oberhausen); Schwab, Robert (Koblenz); Schwandner, Thilo (Lich); Schwarz, Jochen Günter (Rottenburg); Schymatzek, Ulrich (Radevormwald); Spangenberger, Wolfgang (Bergisch-Gladbach); Sperling, Peter (Montabaur); Staade, Katja (Düsseldorf); Staib, Ludger (Esslingen); Stamm, Ingrid (Heppenheim); Stark, Wolfgang (Roth); Stechemesser, Bernd (Köln); Steinhilper, Uz 
(München); Stern, Oliver (Hamburg); Stolte, Thomas (Mannheim); Stopinski, Jürgen (Schwalmstadt); Stubbe, Hendrik (Güstrow/); Stülzebach, Carsten (Friedrichroda); Tepel, Jürgen (Osnabrück); Terzić, Alexander (Wildeshausen); Teske, Ulrich (Essen); Thews, Andreas (Schönebeck); Tillenburg, Wolfgang (Marktheidenfeld); Timmermann, Wolfgang (Hagen); Train, Stefan H. (Gronau); Trauzettel, Uwe (Plettenberg); Triechelt, Uwe (Langenhagen); Ulcar, Heimo (Schwarzach im Pongau); Unger, Solveig (Chemnitz); Verweel, Rainer (Hürth); Vogel, Ulrike (Berlin); Voigt, Rigo (Altenburg); Voit, Gerhard (Fürth); Volkers, Hans-Uwe (Norden); Vossough, Alexander (Neuss); Wallasch, Andreas (Menden); Wallner, Axel (Lüdinghausen); Warscher, Manfred (Lienz); Warwas, Markus (Bonn); Weber, Jörg (Köln); Weiß, Johannes (Schwetzingen); Weißenbach, Peter (Neunkirchen); Werner, Uwe (Lübbecke-Rahden); Wessel, Ina (Duisburg); Weyhe, Dirk (Oldenburg); Wieber, Isabell (Köln); Wiesmann, Aloys (Rheine); Wiesner, Ingo (Halle); Woehe, Fritz (Sanderhausen); Wolf, Claudio (Neuwied); Yildirim, Selcuk (Berlin); Zarras, Konstantinos (Düsseldorf); Zeller, Johannes (Waldshut-Tiengen); Zhorzel, Sven (Agatharied); Zuz, Gerhard (Leipzig);

\section{References}

1. Arias E (2012) United States life tables, 2008. National vital statistics reports, vol 61. National Center for Health Statistics, Hyattsville

2. Wagh PV, Leverich AP, Sun CN, White HJ, Read RC (1974) Direct inguinal herniation in men: a disease of collagen. J Surg Res 17:425-433

3. Pallati PK, Gupta PK, Bichala S, Gupta H, Fang X, Forse RA (2013) Short-term outcomes of inguinal hernia repair in octogenarians and nonagenarians. Hernia 17:723-727

4. Lagoo-Deenadayalan SA, Newell MA, Pofahl E (2011) Common perioperative complications in older patients. In: Rosenthal RA et al (eds) Principles and Practice of geriatric surgery. Springer, Heidelberg, pp 361-376. doi:10.1007/978-1-4419-6999-6_29

5. Burcharth J, Pedersen M, Bisgaard T, Pedersen C, Rosenberg J (2013) Nationwide prevalence of groin hernia repair. PLoS ONE. doi:10.1371/journal.pone.0054367

6. Ruhl CE, Everhart JE (2007) Risk factors for inguinal hernia among adults in the US population. Am $\mathbf{J}$ Epidemiol 165(10):1154-1161. doi:10.1093/aje/kwm011

7. National Medical Registration (2005). Dutch Hospital statistics procedures. http://www.prismant.nl??pag_57. Accessed 29 Aug 2005

8. Simons MP, Aufenacker T, Bay-Nielsen M, Bouillot JL, Campanelli G, Conze J, de Lange D, Fortelny R, Heikkinen T, Kingsnorth A, Kukleta J, Morales-Conde S, Nordin P, Schumpelick V, Smedberg S, Smietanski M, Weber G, Miserez M (2009) European hernia society guidelines on the treatment of inguinal hernia in adult patients. Hernia 13:343-403

9. Hair A, Paterson C, Wright D et al (2001) What effect does the duration of an inguinal hernia have on patient symptoms? J Am Coll Surg 193:125-129
10. van den Heuvel B, Dwars BJ, Klassen DR, Bonjer HJ (2011) Is surgical repair of an asymptomatic groin hernia appropriate? A review. Hernia 15:251-259

11. Akinci M, Ergül Z, Kulah B, Yilmaz KB, Kulacoglu H (2010) Risk factors related with unfavorable outcomes in groin hernia repairs. Hernia 14:489-493

12. Sieber FE, Ryan Barnett S (2011) Preventing postoperative complications in the elderly. Anesthesiol Clin 29(I):83-97. doi:10.1016/j.anclin.2010.11.011

13. Lundström KJ, Sandblom G, Smedberg S, Nordin P (2012) Risk factors for complications in groin hernia surgery. Ann Surg 255(4):784-788

14. Bay-Nielsen M, Kehlet H (2008) Anaesthesia and post-operative morbidity after elective groin hernia repair: a nation-wide study. Acta Anaesthesiol Scand 52(2):169-174

15. Frangou C (2013) Open hernia repair with general anesthesia found less safe in study. General Surgery News, vol 41

16. Gurusamy KS, Vaughan J, Davidson BR (2014) Low pressure versus standard pressure pneumoperitoneum in laparoscopic cholecystectomy. Cochrane Database Syst Rev 3:CD006930. doi:10.1002/14651858.CD006930

17. Cheng Y, Lu J, Xiong X, Wu S, Lin Y, Wu T, Cheng N (2013) Gases for establishing pneumoperitoneum during laparoscopic abdominal surgery. Cochrane Database Syst Rev 1:CD009569. doi:10.1002/14651858.CD009569

18. Farrarese AMDG, Enrico S, Solej M, Falcone A, Catalano S, Gibin E, Marola S, Surace A, Martino V (2013) Transabdominal pre-peritoneal mesh in inguinal hernia repair in elderly: and point of our experience. BMC Surgery 13(Suppl 2):S24

19. Matthews RD, Anthony T, Kim LT, Wang J, Fitzbibbons RJ, Giobbie-Hurder A, Reda DJ, Itani KMF, Neumayer LA (2007) Factors associated with postoperative complications and hernia recurrence for patients undergoing inguinal hernia repair: a report from the VA Cooperative Hernia Study Group. Am J Surg 194:611-617

20. Hernandez-Rosa J, Lo CC, Choi JJ, Colon MJ, Boudourakis L, Telem DA, Divino CM (2011) Laparoscopic versus open inguinal hernia repair in octogenarians. Hernia 15(6):655-658. doi:10. 1007/s10029-011-0838-5

21. Hope WW, Bools L, Menon A, Scott CM 3rd, Adams A, Hooks WB 3rd (2013) Comparing laparoscopic and open inguinal hernia repair in octogenarians. Hernia 17(6):719-722. doi:10.1007/ s10029-012-1013-3

22. Miserez M, Peeters E, Aufenacker T, Bouillot JL, Campanelli G, Conze J, Fortelny R, Heikkinen T, Jorgensen LN, Kukleta J, Morales-Conde S, Nordin P, Schumpelick V, Smedberg S, Smietanski M, Weber G, Simons MP (2014) Update with level 1 studies of the European Hernia Society guidelines on the treatment of inguinal hernia in adult patients. Hernia 18:151-163

23. Bittner R, Arregui ME, Bisgaard T, Dudai M, Ferzli GS, Fitzgibbons RJ, Fortelny RH, Klinge U, Kockerling F, Kuhry E, Kukleta J, Lomanto D, Misra MC, Montgomery A, MoralesConde S, Reinpold W, Rosenberg J, Sauerland S, Schug-Paß C, Singh K, Timoney M, Weyhe D, Chowbey P (2011) Guidelines for laparoscopic (TAPP) and endoscopic (TEP) treatment of inguinal Hernia [International Endohernia Society (IEHS)]. Surg Endosc 25:2773-2843

24. Stechemesser B, Jacob DA, Schug-Paß C, Köckerling F (2012) Herniamed: an internet-based registry for outcome research in hernia surgery. Hernia 16(3):269-276. doi:10.1007/s10029-0120908.3

25. Hafner C, Schweizer M, Schmedt C, Däubler P, Junginger W (2003) Anesthesia in laparoscopic inguinal hernia repair-is ther an age limit? Chir Gastroenterol 19:142-146 